\title{
Clonal stability of latex yield in eleven clones of Hevea brasiliensis Muell. Arg.
}

\author{
K.O. Omokhafe ${ }^{1}$ and J.E. Alika ${ }^{2}$ \\ ${ }^{1}$ Rubber Research Institute of Nigeria, Benin City, Nigeria. \\ ${ }^{2}$ Department of Crop Science, University of Benin, Benin City, Nigeria.
}

\begin{abstract}
Eleven Hevea brasiliensis clones were evaluated for clonal stability of latex yield. A randomized complete block design was used with four replicates, two locations, seven years and three periods per year. Stability analysis was based on clone $\mathrm{x}$ year and clone $\mathrm{x}$ year $\mathrm{x}$ location interactions. Five stability parameters viz environmental variance, shukla's stability variance, regression of clonal latex yield on environmental index, variance due to regression and variance due to deviation from regression were applied. There was significant clone $x$ environment effect at the two levels of interaction. Among the eleven clones, C 162 was outstanding for clonal stability and it can serve as donor parent for stability alleles. Three clones (C 76, C 150 and C 154) were also stable. The four stable clones (C 76, C 150, C 154 and C 162) are suitable for broad-spectrum recommendation for latex yield. Five clones (C 83, C 143, C 163, C 202 and RRIM 600) will require environment-specific recommendation because of their unstable phenotype. The stability feature of two clones (C 145 and C 159) was not clear and this will be investigated in subsequent studies.
\end{abstract}

Key words: Hevea, clones, latex, stability

Received: July 26, 2002; Accepted: June 16, 2003.

\section{Introduction}

Genotype $\mathrm{x}$ environment interaction in Hevea brasiliensis has been reported for latex yield (Goncalves et al., 1992) and several secondary characters (Jayasekera, 1983; Onokpise et al., 1986). Despite the significant genotype $\mathrm{x}$ environment interaction, it is possible to have genotypes that maintain a relatively consistent performance across various environments. Such genotypes are referred to as stable genetic materials.

Several stability parameters have been proposed (Lin et al., 1986) in two major groups. The first group includes environmental variance, which is clone-specific and hence, independent of the population of the test-clones. The second group measures genotypic stability relative to the population of the test-clones. This has two sub-groups, one of which measures linear and non-linear components of stability (Eberhart and Russell, 1966; Finlay and Wilkinson, 1963). The other sub-group includes parameters that measure bulk stability without reference to linear and non-linear components (Plaisted, 1960; Shukla, 1972).

Many high yielding Hevea brasiliensis clones have been developed worldwide (Alika, 1982; RRIM, 1977). In Nigeria, sixteen clones have been selected as commercial

Send correspondence to K.O. Omokhafe. E-mail: kenomokhafe2001@yahoo.com. clones. The latex yield of the Nigerian clones is high at $2000-3500 \mathrm{~kg} / \mathrm{ha} / \mathrm{yr}$ compared to $900-1600 \mathrm{~kg} / \mathrm{ha} / \mathrm{yr}$ of exotic clones (Alika, 1982; Aliyu and Adedipe, 1997). Despite the relatively high latex yield of these clones, clonal stability is important. The yield figures of recommended clones, based on evaluation at the research centre, are often different from yields obtained in different locations. Also, among perennial crops, such as rubber, irregular annual yields make planning difficult. This is more pronounced in unstable clones and stable clones are therefore desired. Hence this study was carried out with the objective of evaluation of clonal stability of latex yield in eleven $H$. brasiliensis clones in Nigeria.

\section{Materials and Methods}

Eleven clones recommended for planting in Nigeria were evaluated at two experimental stations of the Rubber Research Institute of Nigeria (RRIN) over a period of seven years. The clones included ten developed in RRIN and one (RRIM 600) developed in Malaysia (Table 1). The eleven clones were planted in 1979 at each of the RRIN experimental stations. One of the stations was Akwete $\left(5^{\circ} \mathrm{N}\right.$, $7^{\circ} \mathrm{E}$ ) in Abia State (Nigeria) with relative humidity (r. h.) of $58.77 \%$ at 1500 Greenwich Mean Time (GMT). The second location was Etche $\left(4.5^{\circ} \mathrm{N}, 6.5^{\circ} \mathrm{E}\right)$ in Rivers State, Nigeria with mean r. h. of $68.68 \%$ at 1500 GMT. In each 
Table 1 - Parentage of the experimental clones.

\begin{tabular}{lc}
\hline Clone & Parentage \\
\hline C 76 & RRIM $501 \times$ HAR 1 \\
C 83 & RRIM $600 \times$ PR 107 \\
C 143 & RRIM 501 x RRIM 628 \\
C 145 & ditto \\
C 150 & ditto \\
C 154 & ditto \\
C 159 & ditto \\
C 162 & ditto \\
C 163 & ditto \\
C 202 & RRIM $600 \times$ PR 107 \\
RRIM 600 & TJIR $1 \times$ PB 86 \\
\hline
\end{tabular}

location, the experimental design was a randomized complete block design with four replicates and ten trees per clone per replicate. Plant spacing was $3.34 \mathrm{~m} \mathrm{x} 6.7 \mathrm{~m}$.

The plantation, in each location, was opened for tapping in 1991 and latex yield data were collected in three periods of the year for seven years (1991-1997). The periods were January to May, June to September and October to December. The tapping frequency was the half spiral, alternate daily frequency without stimulation (Opeke, 1987). Tapping was carried out at 6.00 to $9.00 \mathrm{~h}$ on each tapping day and data collection was twice a month. The latex from each day of data collection was allowed to undergo auto-coagulation in the latex cup to produce cup-lump. The cup-lumps in a replicate were air dried for twenty-one days and weighed on a $\pm 0.01 \mathrm{~g}$ precision balance. A correction term of 0.53 , as derived from the report of Aniamaka and Olapade (1990), was applied to obtain gram per tree per tapping $(\mathrm{g} / \mathrm{t} / \mathrm{t})$. Latex yield data collection was throughout the year except for a one-month break in February each year. This is the period of severe defoliation of Hevea in Nigeria.
The analysis of variance (ANOVA) for the stability test was conducted as described by Singh and Chaudhaury (1977). In order to enhance the precision of factorial analysis (Omokhafe, 2000), the effect of the three tapping periods per year was a source of variation in ANOVA and it was a component of the average error in stability analysis. Clonal stability was evaluated on the bases of clone $\mathrm{x}$ year and clone $\mathrm{x}$ environment (year $\mathrm{x}$ location) interactions. The average error was calculated as recommended by Eberhart and Russell (1966). Five stability parameters viz environmental variance $\left(\mathrm{S}^{2}\right)$, Shukla's stability variance $\left({ }^{\wedge} \sigma_{\mathrm{i}}{ }^{2}\right)$, regression of clonal latex yield on environmental index $\left(b_{i}\right)$ and the Eberhart and Russell variance due to regression $\left(\mathrm{S}_{\mathrm{bi}}^{2}\right)$ and deviation from regression $\left(\mathrm{S}_{\mathrm{di}}^{2}\right)$ were applied. The formulae for these stability parameters were used as reported by Lin et al. (1986), Shukla (1972), Finlay and Wilkinson (1963) for $\mathrm{S}_{\mathrm{i}}^{2}, \wedge \sigma_{\mathrm{I}}^{2}$ and $\mathrm{b}_{\mathrm{i}}$ respectively. Variance estimates of $\mathrm{S}^{2}{ }_{\text {bi }}$ and $\mathrm{S}_{\text {di }}{ }_{\text {ii }}$ were calculated according to Eberhart and Russell (1966).

\section{Results}

There was no significant clone $\mathrm{x}$ year interaction at Akwete (Table 2). This was accompanied by insignificant non-linear component. However, the linear component of clone $x$ year interaction was significant (Table 3). Despite the insignificant non-linear component, C 83 had significant contribution to the bulk deviation from linearity (Table $3)$. The unstable character of C 83 in Akwete was manifested as it was also detected as unstable by two stability parameters (Table 4).

At Etche, there was significant clone $\mathrm{x}$ year interaction with significant linear and non-linear components (Tables 2 and 3). Six clones (C 83, C 143, C 150, C 163, C 202 and RRIM 600) were rated as unstable by four stability parameters. On the other hand, C 154 was stable for four parameters (Tables 3 and 4).

In combined analysis, clone $\mathrm{x}$ environment interaction was significant (Tables 2 and 5). Both linear and

Table 2 - ANOVA for stability test of Hevea latex yield due to clone x year interaction in Akwete, Etche and combined data.

\begin{tabular}{lcccc}
\hline & & \multicolumn{3}{c}{ Mean squares } \\
\cline { 3 - 5 } S.V. & df & Akwete & Etche & Combined data \\
\hline Total & 76 & $=$ & $=$ & $=$ \\
Year (Year) & 6 & $=$ & 6084.932 & $877.845^{* *}$ \\
Clone (Cl) & 10 & $1936.516^{* *}$ & $555.565^{* *}$ & $31.360^{* *}$ \\
Cl xYr & 60 & 35.960 & $75.028^{* *}$ & $=$ \\
Yr $+(\mathrm{Cl} x$ Yr) & 66 & $=$ & $=$ & $18.698^{* *}$ \\
Pooled deviation & 55 & 28.994 & $51.254^{* *}$ & 10.933 \\
Average error & 210 & 24.952 & 21.599 & $22.48 \%$ \\
Coefficient of variation & & $24.48 \%$ & $34.20 \%$ & \\
\hline
\end{tabular}

**: Significant at $\mathrm{p}=0.01$ (F-test). 
Table 3 - Mean squares of components of clone (Cl) x Year (Yr) interaction of Hevea latex yield in Akwete, Etche and combined data.

\begin{tabular}{|c|c|c|c|c|c|c|c|}
\hline \multirow[b]{2}{*}{ S.V. } & \multirow[b]{2}{*}{$\mathrm{df}$} & \multicolumn{2}{|c|}{ Akwete } & \multicolumn{2}{|c|}{ Etche } & \multicolumn{2}{|c|}{ Combined data } \\
\hline & & SS & MS & SS & MS & SS & MS \\
\hline $\mathrm{Yr}+(\mathrm{Cl} \times \mathrm{Yr})$ & 66 & 8840.848 & $=$ & 41011.288 & $=$ & 18406.148 & $=$ \\
\hline Yr (linear) & 1 & 6683.229 & $=$ & 36509.594 & $=$ & 16524.531 & $=$ \\
\hline $\mathrm{Cl} \times \mathrm{Yr}$ (linear) & 10 & 562.951 & $56.295^{*}$ & 1682.711 & $168.271^{* *}$ & 853.216 & $85.322 * *$ \\
\hline Pooled deviation & 55 & 1594.668 & 28.994 & 2818.983 & $51.254 * *$ & 1028.401 & $18.698^{* *}$ \\
\hline C 76 & 5 & 166.334 & 33.267 & 185.586 & 37.117 & 74.147 & 14.829 \\
\hline C 83 & 5 & 322.947 & $64.589 *$ & 515.981 & $103.196^{* *}$ & 104.131 & 20.826 \\
\hline C 143 & 5 & 24.242 & 4.848 & 338.190 & $67.638^{* *}$ & 115.458 & 23.092 \\
\hline C 145 & 5 & 73.799 & 14.760 & 205.638 & 41.128 & 62.854 & 12.571 \\
\hline C 150 & 5 & 52.884 & 10.577 & 329.326 & $65.865^{*}$ & 71.202 & 14.240 \\
\hline C 154 & 5 & 277.638 & 55.528 & 48.580 & 9.716 & 63.402 & 12.680 \\
\hline C 159 & 5 & 94.578 & 18.916 & 170.960 & 34.192 & 121.332 & 24.266 \\
\hline C 162 & 5 & 42.424 & 8.485 & 79.057 & 15.811 & 42.575 & 8.515 \\
\hline C 163 & 5 & 133.393 & 26.679 & 254.753 & $50.951^{*}$ & 13.206 & 2.641 \\
\hline C 202 & 5 & 212.395 & 42.479 & 271.921 & $54.384 *$ & 146.504 & 29.301 \\
\hline RRIM 600 & 5 & 194.034 & 38.807 & 418.991 & $83.798^{* *}$ & 213.590 & $42.718^{* *}$ \\
\hline Average error & 210 & & 24.952 & & 21.599 & & 10.933 \\
\hline
\end{tabular}

+: Based on Eberhart and Russell's model.

*,**: Significant at $\mathrm{p}=0.05$ and $\mathrm{p}=0.01$ respectively ( F-test). MS for each clone $=\mathrm{S}^{2}$.

non-linear components were significant in clone $\mathrm{x}$ year interaction (Table 3) while only the non-linear component was significant in clone $\mathrm{x}$ environment (year $\mathrm{x}$ location) interaction (Table 5). Clone C 162 was stable for four stability parameters in clone $\mathrm{x}$ year interaction and for all the five stability parameters in clone $\mathrm{x}$ environment (year $\mathrm{x}$ location) interaction (Tables 3, 4 and 5). Three clones (C 76, C 150 and $C$ 154) were stable for four stability parameters in clone $\mathrm{x}$ year interaction (Tables 3 and 4).

In each location, clonal variation was significant with yield range of 16.67-33.63 $\mathrm{g} / \mathrm{t} / \mathrm{t}$ at Akwete and 19.38-29.64 g/t/t at Etche (Tables 2 and 4). Clonal variation was also significant in combined analysis with yield range of 20.18-31.30g/t/t/ (Tables 2 and 4).

\section{Discussion}

The application of five stability parameters derived from the different stability groups enhanced the inference drawn on clonal stability for latex yield in each of the test-clones. The controversy that often arises with different criteria at various times has been minimized in this study. Fears of bias of the individual parameters have been expressed (Lin et al., 1986).

The significant linear and non-linear components of the clone $\mathrm{x}$ environment interaction were an indication of the importance of both predictable and unpredictable clonal response to the various environments. The unpredictable (non-linear) pooled deviation made the clonal contribution to unpredictable components an imperative. This was such that C 162 was an outstanding clone for clonal stability. This was followed by C 154, C 76 and C 150 in descending order. According to Singh and Gupta (1988), clonal/variety stability has genetic control. The clone C 162, therefore, could be used as a parent-in-crosses to transfer genetic stability for latex yield to progenies. For commercial planting, C 162, C 154, C 76 and C 150 merit broad-spectrum recommendation because of their likelihood of relatively consistent latex yield across different environments. Conversely, C 83, C 143, C 163, C 202 and RRIM 600 will require environment-specific recommendation. This is more so as consistently high latex yield across various years and locations is desired by farmers. Clonal variation for latex yield suggests possible selection for latex yield among these clones.

The clone RRIM 600 was rated unstable in the present study by Goncalves et al. (1999). Meenattor et al. (1991) reported RRIM 600 stable for girth increment. These results suggest that clonal stability could vary depending on the character under consideration.

Despite the common parentage of C 143, C 145, C 150, C 154, C159, C162 and C 163, these clones exhibited different stability features. The entire range of clonal stability from highly stable clone (C 162) to intermediate (C 150 and C154) and unstable (C 143 and C 163) was manifested among the progenies of the same cross (RRIM $501 \times$ RRIM 628). This suggests high heterogeneity in the parental clones, hence heterogenous progeny were produced. In addition, it supports the opinion of Omokhafe (1998) that 


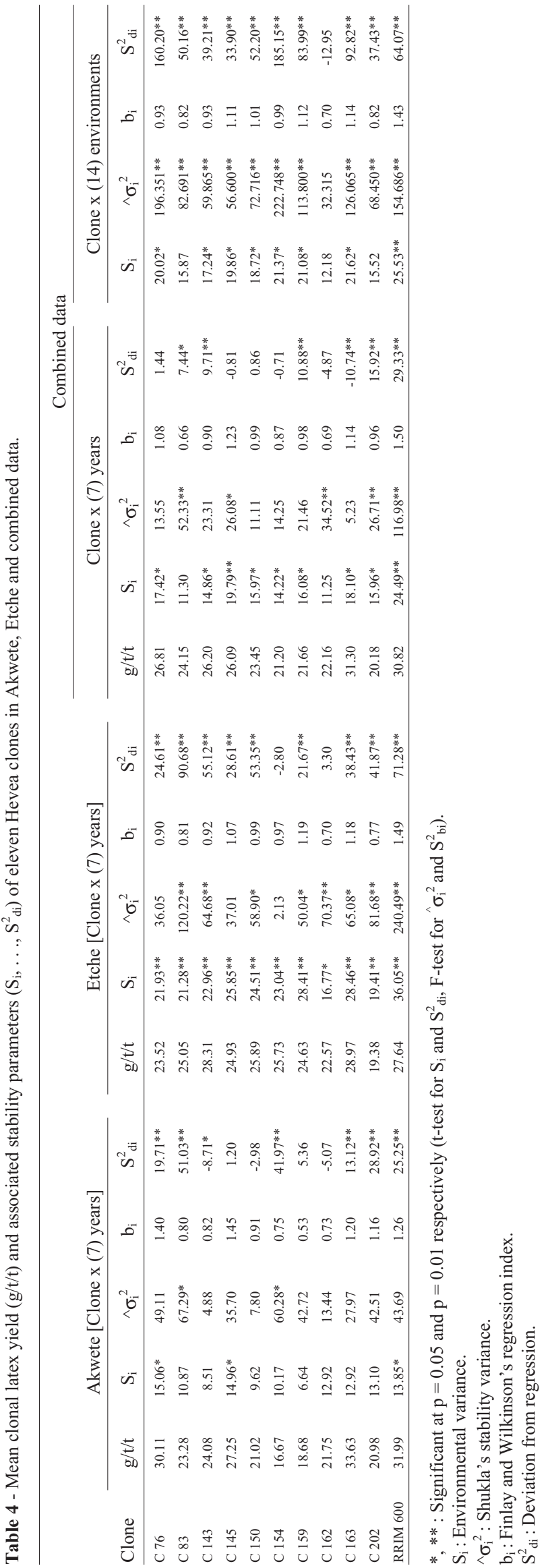

Table 5 - Components of stability mean squares of latex yield of eleven Hevea clones (Cl.) in 14 environments (Env.)-seven years $\mathrm{x}$ two locations (Akwete and Etche)-Eberhart and Russell model.

\begin{tabular}{lrrc}
\hline S.V. & df & \multicolumn{1}{c}{ SS } & \multicolumn{1}{c}{ MS } \\
\hline Total & 153 & 75016.880 & 490.306 \\
Env. & 13 & 43436.763 & 3341.289 \\
Clone (Cl.) & 10 & 17557.539 & $1755.754^{* *}$ \\
Cl. x Env. & 130 & 14022.578 & $107.866^{* *}$ \\
Env. + (Cl. x Env.) & 143 & 57459.341 & $=$ \\
Env. (linear) & 1 & 43436.763 & $=$ \\
Cl. x Env. (linear) & 10 & 1516.285 & 151.629 \\
Pooled deviation & 132 & 12506.293 & $94.745^{* *}$ \\
C 76 & 12 & 2201.653 & $183.471^{* *}$ \\
C 83 & 12 & 881.210 & $73.434^{* *}$ \\
C 143 & 12 & 749.806 & $62.484^{* *}$ \\
C 145 & 12 & 686.049 & $57.171^{* *}$ \\
C 150 & 12 & 905.752 & $75.479^{* *}$ \\
C 154 & 12 & 2501.091 & $208.424^{* *}$ \\
C 159 & 12 & 1287.200 & $107.267^{* *}$ \\
C 162 & 12 & 123.882 & 10.324 \\
C 163 & 12 & 1293.147 & $107.762^{* *}$ \\
C 202 & 12 & 728.410 & $60.701^{* *}$ \\
RRIM 600 & 12 & 1048.093 & $87.341^{* *}$ \\
Average error & 420 & & 23.275 \\
\hline & & & \\
\hline & 12 Sign & & \\
\hline
\end{tabular}

**: Significant at $\mathrm{p}=0.01$ (F-test).

MS for each clone $=\mathrm{S}_{\mathrm{bi}}^{2}$.

evaluation and selection in Hevea brasiliensis should be based on individual selection rather than family selection.

\section{Acknowledgment}

The authors are grateful to the field staff of Plant Breeding Division and the Akwete sub-station of the Rubber Research Institute of Nigeria for maintaining the field trials. The assistance of Mr. Benson Onyeanakwe in data collection and collation is hereby acknowledged.

\section{References}

Alika JE (1982) Preliminary assessment of some hand pollinated progenies of rubber in Nigeria. Indian J Agric Sci 52:367369.

Aliyu A and Adedipe NO (1997) Directory of commercialisable findings of Nigerian Agricultural Research Institutes, National Agricultural Research Project, Abuja, pp 84-94.

Aniamaka EE and Olapade EO (1990) Comparison of different methods of yield estimation in Hevea brasiliensis. Indian J Nat Rubb Res 3:98-101.

Eberhart SA and Russell WA (1966) Stability parameters for comparing crop varieties. Crop Sci 6:36-40.

Finlay KW and Wilkinson GN (1963) The analysis of adaptation in plant breeding programme. Aust J Agric Res 14:742-754. 
Goncalves PDS, Cardoso M, Santos ICID, Martins ALM, Ortolani A and Colombo CA (1992) Selection of Hevea mother trees adapted to unpredictable annual climatic variability. Rev Brasil Genet 15:137-147.

Goncalves PDS, Fujihara AK, Ortolani AA, Bataglia OC, Bortoletto N and Segnini-Junior I (1999) Phenotypic stability and genetic gains in six year girth growth of Hevea clones. Pesq Agropec Bras 34:1223-1232.

Jayasekera NEM (1983) A basis for selecting Hevea clones stable to unpredictable agro-climatic variability. Silvae Genettica 32:5-6.

Lin CS Burns MR and Lefkovitch LP (1986) Stability analysis: Where do we stand? Crop Sci 26:894-900.

Meenattoor RT, Vinod KK, Krishnakumar AK, Sethuraj MR, Potty SN and Sinha RR (1991) Clone x environment interaction during early growth phase of Hevea brasiliensis I. Clonal stability on girth. Indian J Nat Rubb Res 4:51-54.

Omokhafe KO (1998) Variation and phenotypic correlation of five morphological characters in a population of Hevea genotypes developed in RRIN. Nig. J Hort Sci 3:117-123.
Omokhafe KO (2000) Development of appropriate vigour index for immature Hevea brasiliensis. Nig J Applied Sci 18:2932.

Onokpise OU, Olapade O and Mekako HU (1986) Genotype x environment interaction in Hevea brasiliensis Muell. Arg. Indian J Genet 46:506-514.

Opeke LK (1987) Tropical tree crops, Spectrum Books Ltd., Ibadan, Nigeria.

Plaisted RL (1960) A shorter method for evaluating the ability of selections to yield consistently over locations. Am Potato J 37:166-172.

RRIM (1977) Evironmax planting recommendations. Planters Bull 1977-1979:163-182.

Shukla GK (1972) Some statistical aspect of genotype-environment components of variability. Heredity 29:237-245.

Singh RK and Chaudhaury BD (1977) Biometrical methods in quantitative genetic analysis, Kalyani Publishers, India.

Singh SV and Gupta PK (1988) Phenotypic stability for tuber yield in potato (Solanum tuberosum L.). Indian J Genet 48:9-12.

Editor: Marcio de Castro Silva-Filho 